\title{
Design and Use of Interactive Social Stories for Children with Autism Spectrum Disorder (ASD)
}

\author{
Sunagul Sani-Bozkurt, Sezgin Vuran, \& Yavuz Akbulut \\ Anadolu University, Turkey
}

\begin{abstract}
The current study aimed to design technology-supported interactive social stories to teach social skills to children with autism spectrum disorder (ASD). A design-based research was implemented with children with ASD along with the participation of their mothers, teachers, peers and field experts. An iterative remediation process was followed through the feedback of participants. The data collection process was further supported through researcher notes, interviews, video-recorded observations and log files. Three cycles of remediation were employed to improve the interactive materials, which lead them to be perceived as pleasant, interesting, engaging and user-friendly. It was observed that children gained useful non-target skills as well as the target behaviors. Interactive stories were particularly helpful in raising satisfaction as they provided children with the opportunity to make their own learning decisions.
\end{abstract}

Keywords: Autism spectrum disorder; Multimedia learning; Interactive social stories; Instructional design for special education; Learners with special needs

\section{Introduction}

Information and communication technologies (ICT) became widespread in several fields in the $21^{\text {st }}$ century including educational settings. It changed paradigms in education, which required revising instructional materials accordingly. Internet and mobile technologies triggered these changes further. Such transformations require new information-based tools and software to be created as well (Kagohara, Sigafoos, Achmadi, O’Reilly, \& Lancioni, 2012; Ramdoss et al., 2012).

Recent technological transformations have also been adopted by the special education field. For instance, Herbert (2010) underlines the importance of ICTs and particularly mobile technologies in creating a reform in special education practices. Computers and computer-based systems, virtual reality, multimedia, interactive videos and many other advanced tools can be stated as examples to illustrate ICTs' potential to create effective learning environments for individuals with special needs. Furthermore, robust theoretical frameworks have been proposed in relevant fields including the multimedia learning approach, which considers individual differences and learning characteristics while developing technology-rich and effective instructional designs.

Scholars who are interested in methods to cope with the Autism Spectrum Disorder (ASD) can also adopt recent technology-rich implementations to ameliorate the instructional atmosphere. In the Diagnostic and Statistical Manual of Mental Disorders, ASD is defined as a neurodevelopmental disorder marked by deficits in the areas of social communication and other cognitive and motor behaviors (American Psychiatric Association, 2012). The novelty effect 
stemming from the use of recent technological tools is likely to sustain higher levels of interest among individuals with ASD. In this regard, teaching several social, psychomotor and academic skills can be facilitated through the use of these tools. For instance, spelling, counting, drawing, solving puzzles, recalling pictures and matching objects are frequently used activities among learners with ASD. These activities are easily employed through the help of current technological devices such as mobile phones and tablet PCs. Accordingly, recent work reveal that such devices are quite user-friendly, affordable and sustain higher and more realistic control over the instructional content (Gentry, Lau, Molinelli, Fallen, \& Kriner, 2012; Johnson et al., 2013; Shah, 2011). In addition, they facilitate individualized learning opportunities for the learners with ASD (Chen, 2012).

Interactive social stories are one of the potential areas that can easily be employed through the help of mobile devices. Rule and procedure learning through social stories is a common method in special education practices. Affordances of mobile devices along with recent advances in data compression and graphic design technologies help practitioners to employ social stories through portable devices, and to provide learners with real-like interaction opportunities. In this regard, the current manuscript investigates the use of interactive social stories for skills-training among individuals with ASD through resorting to the theoretical frameworks on interactive multimedia and social story use for instructional purposes.

\section{Multimedia Learning and Social Stories}

The multimedia learning approach addresses learning through verbal and audio-visual materials (Mayer, 2005). Several studies suggest that meaningful learning is sustained through providing content verbally and audio-visually (Houghton \& Willows, 1987; Mandl \& Levin, 1989; Schnotz, 1993). That is, the content should be presented through multiple modes to empower learning (Mayer \& Sims, 1994), which is explained through a dual-coding model (Paivio, 1990; Mayer, 1997; Mayer \& Moreno, 1998; Moreno \& Mayer, 1999). This model underlines the limited capacity of the short term memory (Miller, 1956), and argues that the content should be transmitted through verbal and audio-visual channels. The idea is using multiple channels to facilitate processing without causing a cognitive load (Sweller, 1988). As multimedia triggers multiple sensory channels, the burden on a single channel is prevented which increases the effectiveness of digital learning materials. Unless the same and redundant information is presented through multiple channels, presenting the information through both verbal and audio-visual ways helps learners to create both models in their minds, and to establish a meaningful relationship between them.

Another factor that facilitates learning in multimedia is interaction. Learners can reach different types of contents (e.g., texts, graphics, animations, images, videos, sounds) interactively and easily. That is, rather than just watching the content, the learner can actively select or even manipulate it in accordance with their learning preferences. Multimedia applications can facilitate such an interaction where the materials become more effective and interesting (Mukti \& Hwa, 2004).

As the use of interactive multimedia for instructional purposes revealed positive results in the literature, the idea of using them for special education has been brought to agenda. This trend was particularly relevant for individuals with ASD, as they can perceive visual stimuli more easily than the audio materials (Rao \& Gagie, 2006; Shukla-Mehta, Miller, \& Callahan, 2010). One of the methods to sustain such a modality-rich instruction is the implementation of social stories 
(Gray 2010; National Autism Center [NAC], 2015). These short stories are written in a specific format to address certain social rules and illustrate the appropriate ways to react in different social contexts (Gray, 2010; Gray \& Garand, 1993). These stories can be presented through text or visuals (Goodman-Scott and Carlisle, 2014; Gray, 2010; Karkhaneh et al., 2010).

During the first years of the use of social stories, Gray and Garand (1993) stated that they should not contain visual stimuli, and argued that each sentence creating the story should be presented on separate pages. However, they modified their view in 1995, and stated that adding visual stimuli to support the story could improve the transmission of the message particularly for individuals with dyslexia (Wheeler, 2005). In this regard, social stories can be presented with music (Brownell, 2002), video models (Sansosti \& Powell-Smith, 2008) or computer-aided technologies (Hagiwara \& Myles, 1999).

\section{Interactive Social Stories}

The fictional setup addressed in individual social stories can be supported through emerging multimedia tools easily (Garzatto, 2010). That is, the interaction is sustained since multimedia tools facilitate the presentation, selection and manipulation of the instructional content. Giving the children the opportunity to start, stop, create or edit the content is easier through such emerging tools, which leads to a more authentic learning experience (More, 2008). Therefore, the greater the interaction level, the more effective and authentic the learning.

In the current study, interactive social stories are regarded as the adapted version of traditional social stories. That is, through resorting to emerging mobile technologies, the content is presented in a multimedia-rich environment where static and dynamic visuals are empowered through audio and textual materials (Lundby, 2008). In addition, there is an opportunity for bidirectional interaction, sustaining a mutual communication between the user and the content. More specifically, the individuals with the ASD navigate through the multimedia content in accordance with their media preferences along with their responses to the chunks of the story. That is, rather than receiving a monotonous content passively, they participate actively in selecting relevant materials and alternative directions of the story. In this regard, individuals with ASD can gain their autonomy, and can process the social story content through trial-anderror, and exploration in a safe learning environment similar to real life (More, 2008).

The literature review reveals that social stories are generally used with traditional methods for skills teaching to individuals with ASD (Richter \& Test, 2011). While multimedia-rich contents have been used with similar target populations (Hagiwara \& Myles, 1999; Ozdemir, 2008; Sansosti \& Powell-Smith, 2008), except for one doctoral dissertation (Sani-Bozkurt, 2016), no studies have been identified which employed interactive social stories. One of the obstacles to using this method is the absence of relevant methods and content for the target group. Yet, the fictional nature of these stories and affordances of emerging multimedia tools make it convenient to create authentic and interactive social stories. In this regard, the current study aims to investigate the ways to present interactive social stories through tablet PCs. The following research questions will be addressed:

1. How should social stories be designed and presented in interactive media while teaching social skills to adolescents with ASD?

2. What are the views of the participants regarding the usability of the interactive social stories? 


\section{Method}

The design-based research method was employed to prepare interactive social stories. Designbased research is an approach that blends design and practice with empirical steps (Brown, 1992; Collins, 1992; Hoadley, 2005). It is a design process that diversifies different data resources and establishes a connection with targeted and non-targeted outcomes. The advantage of the process is the integration of educational practices with theoretical foundations. To sustain this integration, researchers work together with those who implement the methods (Schwartz, Lin, Brophy, \& Bransford, 1999; van den Akker, 1999; Wang \& Hannafin, 2005). Thus, the gap between design, theory, and practice is eliminated (Barab, 2006; Barab \& Squire, 2004; DesignBased Research Collective, 2003).

The design-based research is a systematic and flexible research method in which analysis, design, development, and implementation are conducted in a real environment with the cooperation of researchers and participants. Such an approach improves training practices and help to develop context-sensitive design principles (Barab, 2006; Barab \& Squire, 2004; Shavelson, Phillips, Towne, \& Feuer, 2003; Wang \& Hannafin, 2005). Such design-based endeavors have five basic characteristics. They are pragmatic; grounded in a theoretical basis; interactive, repetitive, and flexible; and integrated and contextual (Wang \& Hannafin, 2005). Furthermore, it is feasible to propose three different outcomes using a design-based research method (Design Based Research Collective, 2003). First, the method can be used to develop innovative learning environments. Second, it can be used to develop new classroom exercises. Finally, it can be used to propose new learning theories. In this regard, the current study aims to develop both an innovative learning environment and alternative classroom exercises for individuals with ASD.

Different models were developed to implement design-based studies (Bannan-Ritland, 2003; Reeves, 2000). In the current study, a four-phase circular model proposed by Reeves (2000) was adopted, since it fits the research context better. Below, implementation of this model within the current research context is explained and justified in detail.

\section{Design-based Research: Social Story Designing Process}

An interactive social story was developed after determining relevant parameters in accordance with the research questions (i.e., characteristics of individuals with ASD, content design, interface design, multimedia, and interaction design principles).

The first phase of the current research is "analysis." The steps followed in this phase are summarized as follows:

- Literature review: Available studies were analyzed first. Studies that were likely to contribute to the current social story practice were identified. The theoretical frameworks relevant to designing interactive social stories were determined. In this regard, two different interaction choices, content interaction and interface interaction, were selected and applied. Further theories and concepts such as multimedia learning, communication media richness, cognitive load, and dual coding were examined. In terms of the interface design, several principles are taken into account such as physical (e.g., balance, symmetry, regularity, alignment, proportion, horizontality), composition 
(e.g., simplicity, economy, neutrality, singularity, positivity, transparency), association and dissociation (e.g., unity, repartition, grouping, and sparing), ordering (e.g., consistency, predictability, sequentiality, continuity), and imaging and photograph (e.g., sharpness, roundness, stability, representation, subtlety, leveling, realism, flatness). On the other hand, the basic principles and characteristics of the social story, together with social story writing techniques, were taken into consideration while designing the content.

- Conducting a needs analysis: The needs analysis was performed through addressing two basic dimensions. The first dimension was about the needs related to choosing a social skill and writing a social story. The second dimension was the needs about designing these stories through interactive media. The researchers made direct observations in environments where target students spend time (e.g., classroom, school garden, home). Families and teachers were interviewed as well. The social story topics were identified as 'game participation' and 'coping with mockery', which were selected through the social skill check-lists completed by families and teachers. Then, social stories for these skills were written. While writing the story statements, secondary school students in the same age and education group with typical development were interviewed. A statement pool addressing the target behaviors and reactions were prepared.

Characters, activities, background features, figure-background relations, and the training period were determined according to family, peer and teacher feedback. Direct observations were also helpful. In addition, buttons, choices, audio recordings, and sound effects to be used were determined through teacher and expert opinions. The interaction elements of the social story were designed through considering the characteristics and developmental levels of the target individuals with ASD.

- Expert views: After determining the typical statements to be included in social stories, the writing phase was initiated. In this regard, social story writing rules described by Gray (2010) were employed. Besides, three scholars with PhDs in special education who had extensive experience in terms of social stories were interviewed for feedback regarding statement types, number of statements, clarity and comprehensibility. In addition, the title, introduction, progression, and result sections were reviewed along with the reading comprehension questions. To identify the expert views, a social story writing form was used. Based on the feedback, certain words and order of statements were revised, and the number of sentences was reduced. Visuals to be designed for these scenarios were also decided through opinions of seven experts from the fields of special education, instructional design, graphic design and distance education. These experts commented on the suitability of the scenarios and visuals, which further helped researchers to determine design and development components such as the use of buttons, symbols, colors, characters and the learning environment.

The second phase is "design and development", which consisted of three remediation cycles as summarized below:

- The first remediation cycle involved the design of the first social story prototype to be presented through tablet PCs. This sample involved the final scenarios determined through expert opinions along with the accompanying visuals. In the prototype, individuals' self-introduction skills were addressed. A one-week pilot study was 
conducted in a natural environment through the participation of three children with ASD. These children did not participate in the subsequent steps of the research. Based on the observations and teacher comments, the transition page to the reading comprehension questions, and the introduction page were revisited to increase user friendliness for the target group. Furthermore, navigation choices were re-adjusted based on the usage behaviors of the pilot group.

In order to create interactive social stories, the "Articulate Storyline" program was the first option to be used. However, since the characters in this program did not let researchers to add relevant gestures and facial expressions appropriately, the research team decided to use "Cordova" instead. The new program offered more flexible options compared to the previous choice. Particular attention was given to keep balanced gender distribution among the characters. Besides, appearance of the characters and colors of outfits were chosen in accordance with typical school uniforms used in target settings. Pastel colors were preferred rather than vivid ones in order to minimize the distraction of users. Furthermore, the voice of a peer at the same age, gender and education group was preferred in the social stories. After the target voice for narration was determined through interviewing several candidates, the narrator was trained for a week to increase the quality of the social stories. Finally, log records were decided to be stored in order to track the interaction of users with the interface.

During this remediation cycle, the data were collected through interviews on prototype contents, visual design features and usability comments. Besides, natural observations, personal notes of the students and the researcher diary were taken into consideration. The data were analyzed and assessed by experts in the fields of special education, instructional design and distance education. Their comments were particularly helpful to improve the design of the material.

- The second remediation cycle involved another pilot study before the experimentation. Five students with ASD participated in this implementation. The pilot was just like the first remediation cycle, which helped researchers to fine-tune the materials. Data collected through video-recordings, log data, observation, researcher diaries, teacher comments and student notes. Based on the findings, the user guide was re-designed through composition changes and additional explanations. For instance, when a button was used the first time, its function was described through verbal and visual explanations. In brief, triangulation of the data regarding material usability helped the researchers to improve the materials. All usage data obtained through the log files and the qualitative data obtained through diaries and participant interviews were used to examine the usability of the prototype, which was further assessed by an expert panel to eliminate potential problems in subsequent usage experiences.

- The third remediation cycle resorted to the usage data of five participants with ASD again. Feedback from their teachers and primary caregivers was used to identify negative views or problems regarding the material. As they made no further negative views to improve the system, the prototype was finalized.

The third phase is "implementation and assessment."

- The developed materials were administered to four students with ASD, who were enrolled in an inclusion training. The study was conducted in a real learning environment 
similar to the context of the social stories. In this phase, the prototype was administered and findings were analyzed for three times in natural settings. All applications were video recorded in addition to researcher observation notes, student views, teacher and parent interviews, and the log data.

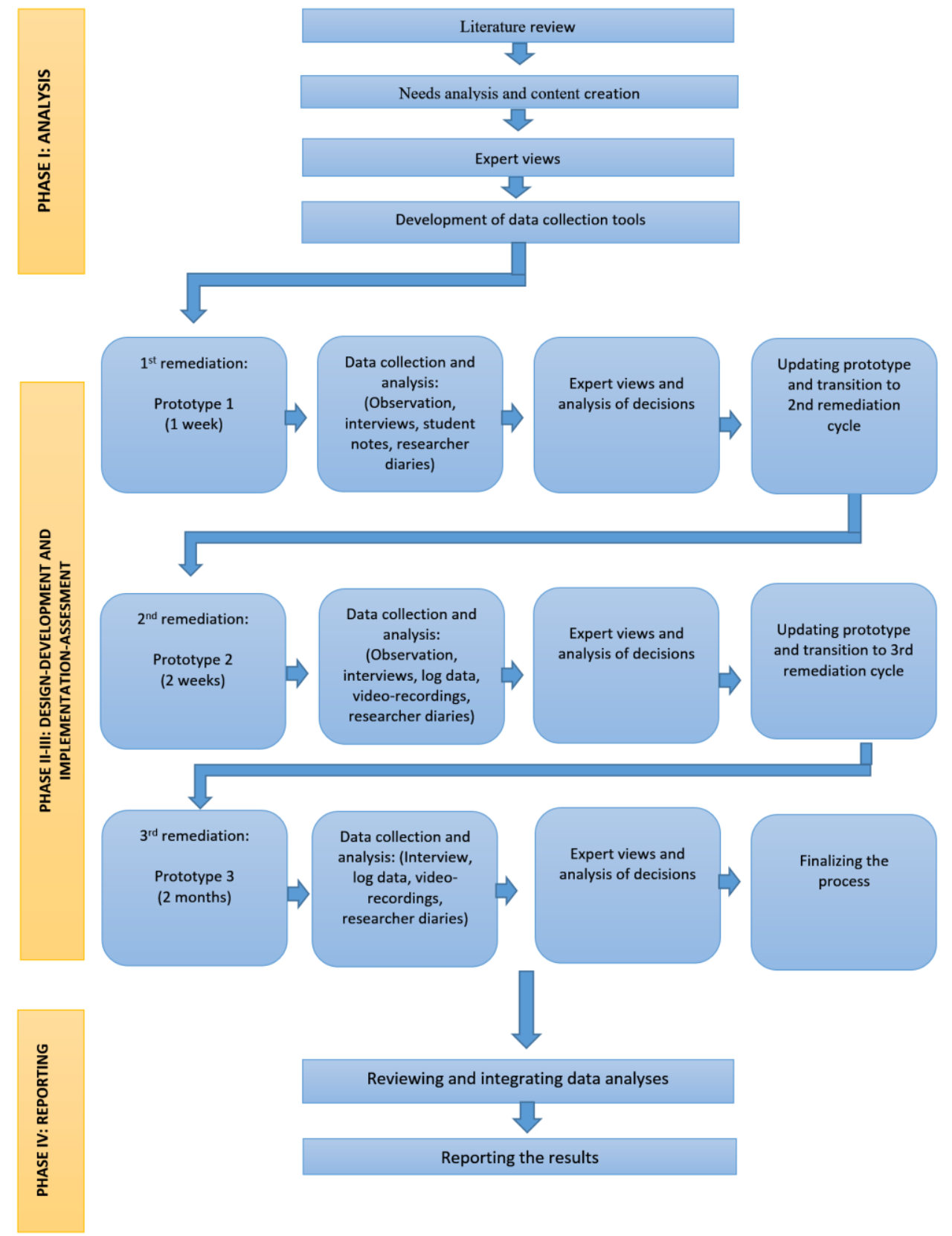

Figure 1. Design-based Resarch Process

The fourth phase involved "making the required changes in the light of current findings and reporting the results."

- During this final phase of the research, all data analyzed in the first three remediation cycles were reviewed, the data were linked, and the results were reported. 
- The changes required in the light of data were employed in accordance with research findings. The aim of the changes was not only to remedy deficiencies, but also to improve the material with new design decisions.

\section{Introduction of the Interactive Social Stories}

Two interactive social stories were prepared to address "participation in games" and "coping with mockery". Interactive social skill practices were implemented for both topics. As an example of the current design outcomes, the interactive social story on "participation in games" is illustrated in subsequent paragraphs.

Page 1: User login: The practice begins with the user page where the participant name is entered. As soon as the name is entered, the software records user data such as how many times a particular button is hit, how much time is spent on each page, duration of the training for the whole story, and the number of correct or incorrect responses. This data can further be used for learning analytics to investigate interaction patterns in depth. Such a practice may improve the design decisions and increase effectiveness in subsequent uses of the material.

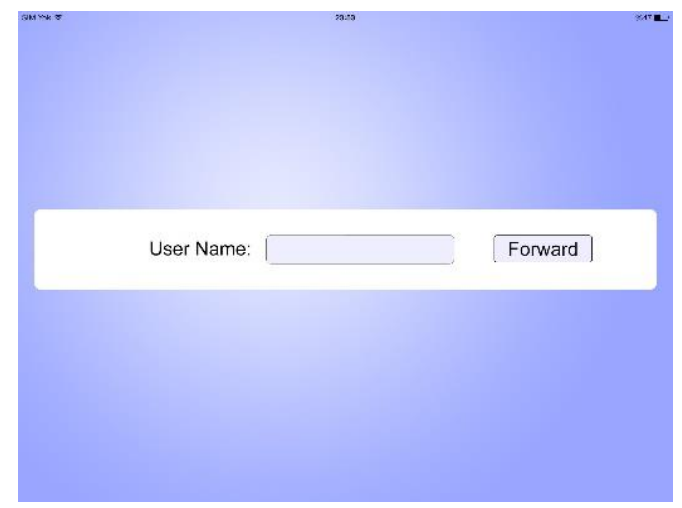

Figure 2. Login Page

Page 2: Transition and preparation: The page with the story title appears after the login page. The participant may read the content or prefer to listen as well. With the "start" button, the participant proceeds with the social story application.

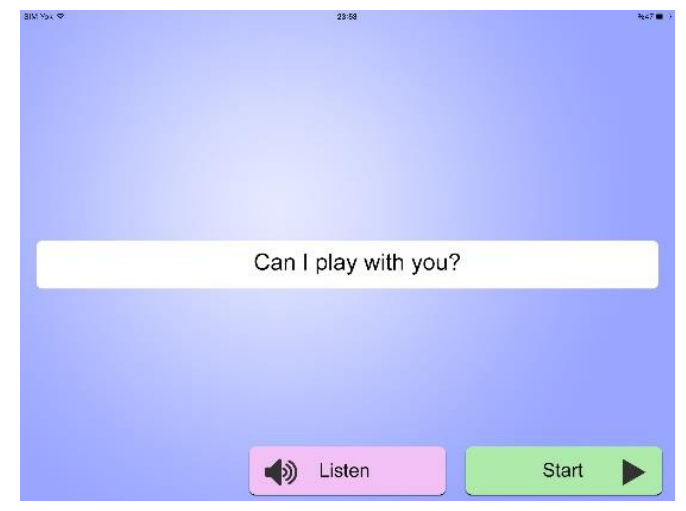

Figure 3. Transition and Preparation 
Page 3: User guide: Before proceeding with the social story, the participant sees a page where buttons for navigation and interaction are introduced. Here, participants are given an opportunity to experience the application. When a participant hits a button, the button comes into focus and the functions of the button are explained through both verbal stimulus and the voice of a peer from the same age group.

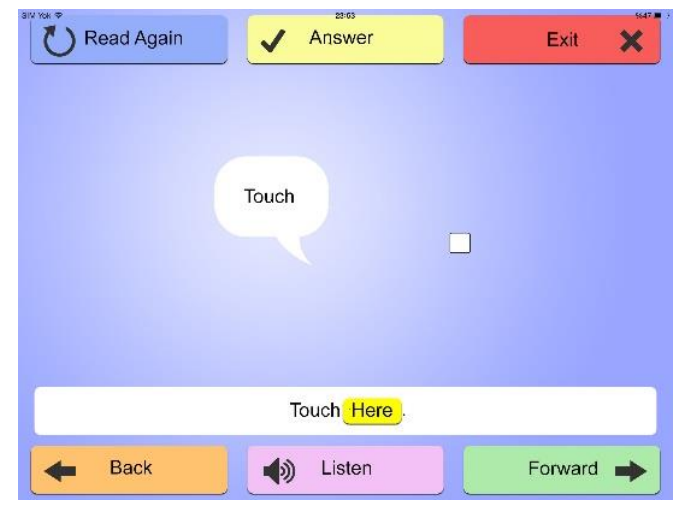

Figure 4. User Guide

Page 4: Title page: On this page, the title of the story is explained by an animated character who had the appearance of a peer from the same age with the participant. The voice-over version of the written story can be accessed through hitting the title. Through hitting the "read" button, the participant can initiate the social story.

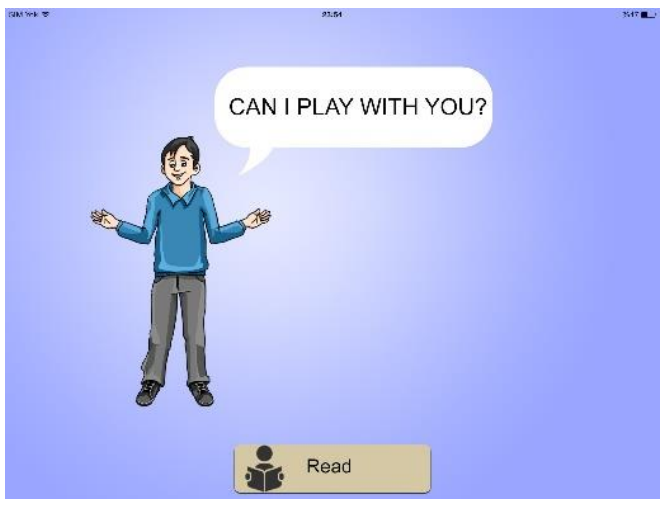

Figure 5. Title Page

Page 5 through 11: Interactive social story pages: On pages 5 through 11, the social story is presented. These pages contain "next," "back," and "listen" buttons. Verbal, visual, and audio versions of the content are presented based on the individual learning differences of the participants. The audio version of the content was added as an option in order not to cause cognitive load on the students. The parts intended to be emphasized were highlighted, and a separate audio content option was offered for these highlighted parts. Furthermore, both visual and audio options were given for speech balloons. On these pages, participants can interact select from a variety of sensory modalities which are supposed to provide interaction opportunities. 
On page 5, participants are asked to choose how the story will proceed. Accordingly, two parallel scenarios were created. On this page, a process called "branched story" or "interactive fiction" is applied. This process gives participants the opportunity to choose the next phase of the story and to decide how the story will proceed. For instance, in the branched story for the "participation in games" version, two alternatives are provided under the sentence "Choose who you want to play with". This allowed participants to choose playmates who are playing two different games. On the other hand, for the "coping with mockery" version, participants can decide between a teacher / peer for the statement "I tell my teacher / peers what has happened". The story proceeds with the game or character chosen by the participants. These preferences realized by participants help them to internalize the story content and feel active in the story.
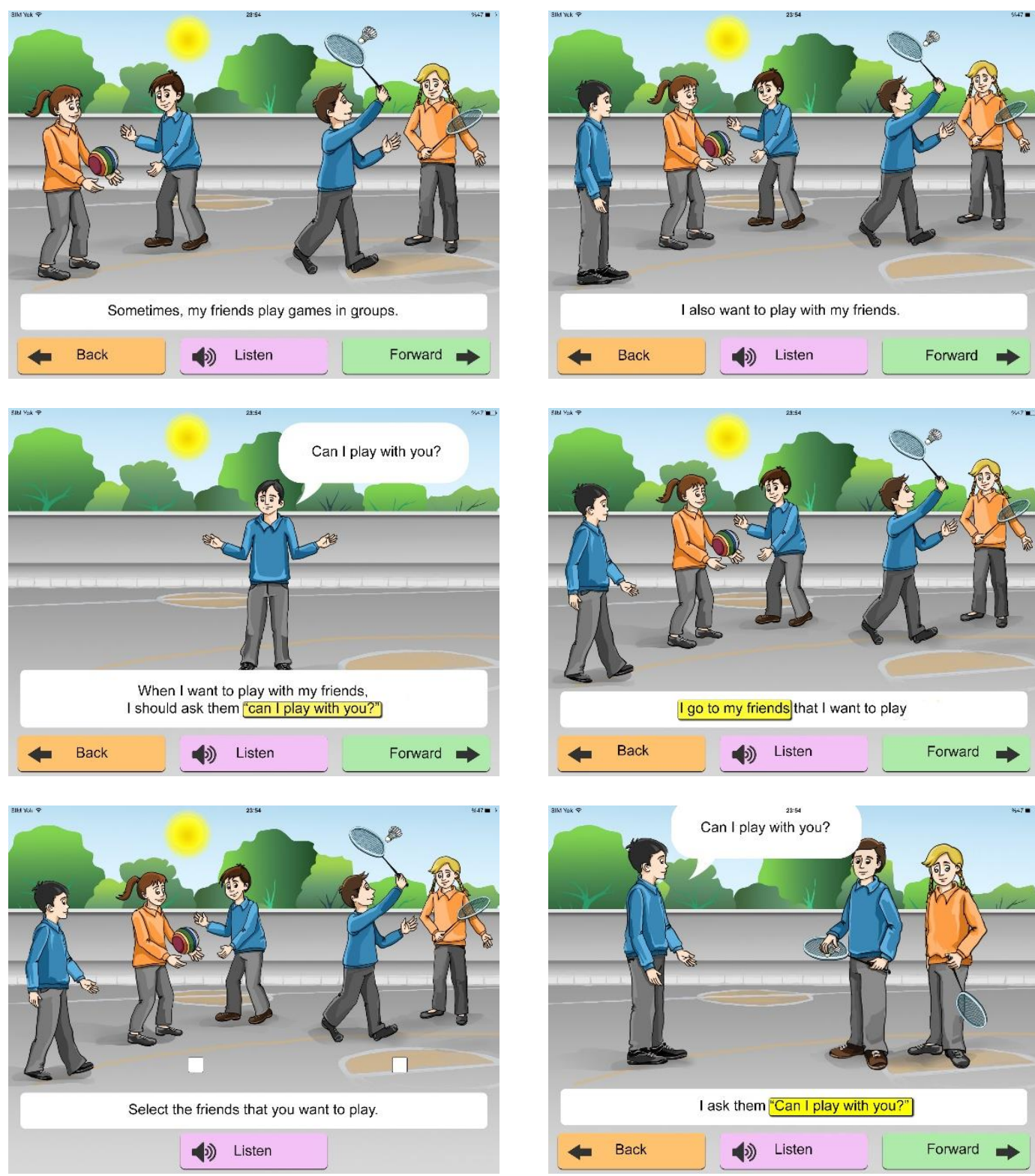

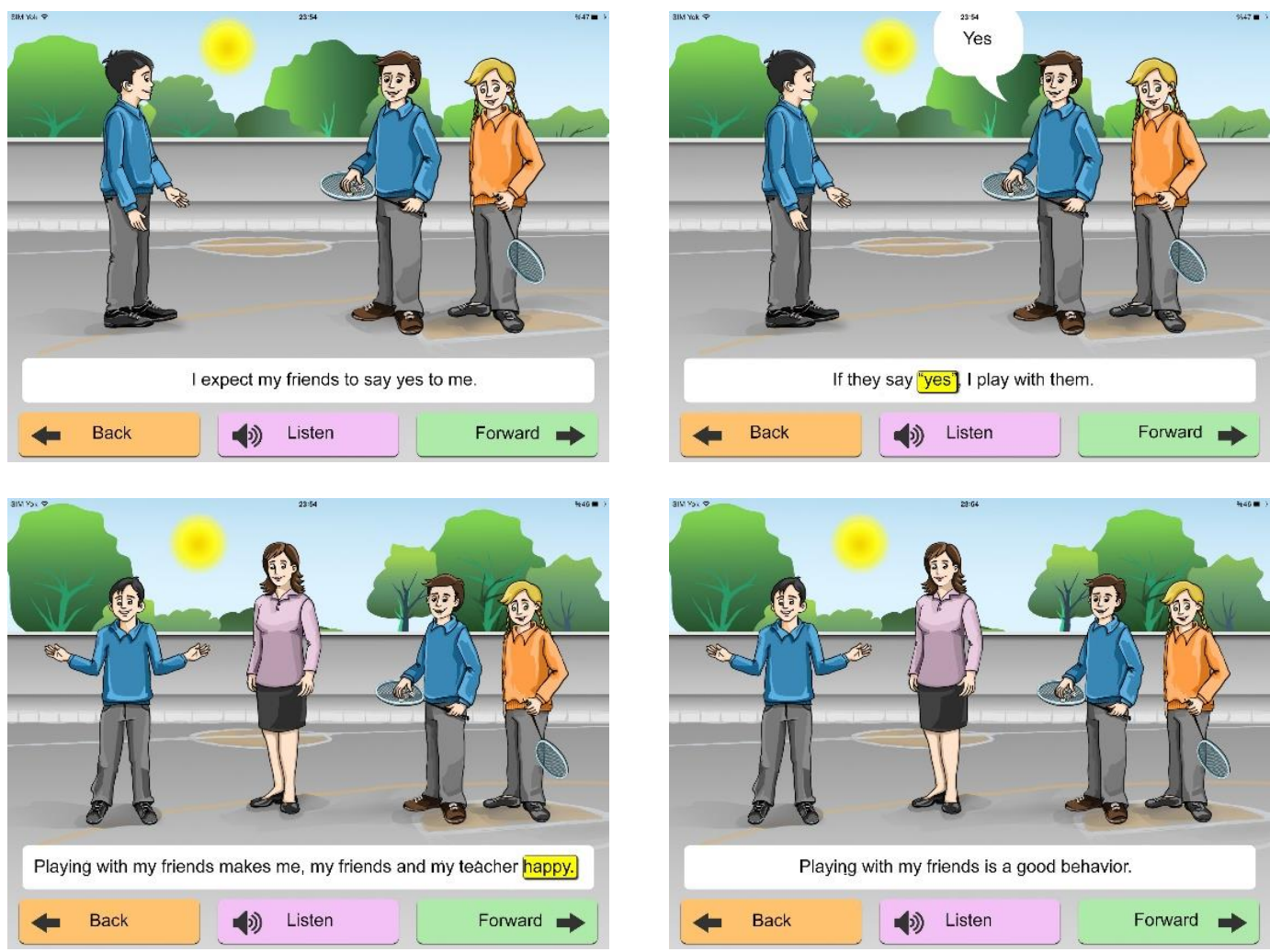

Figure 6. Interactive Social Story Pages

Page 12: Decision page: On page 12, participants are given the opportunity to re-read the social story or answer reading comprehension questions.

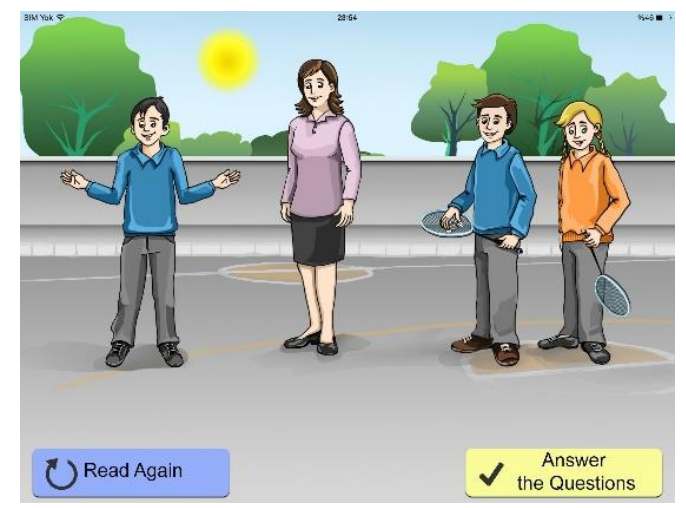

Figure 7. Decision Page

Page 13 and 15: Reading comprehension questions: Reading comprehension questions were prepared to check comprehensibility of the social story by the participants. Participants were asked to check the correct button while answering the questions. Feedback on the correct and incorrect answers were provided through visual and audio stimuli. In the case of incorrect answers, the pages involving the correct answers are displayed automatically, and participants were asked to answer again. 

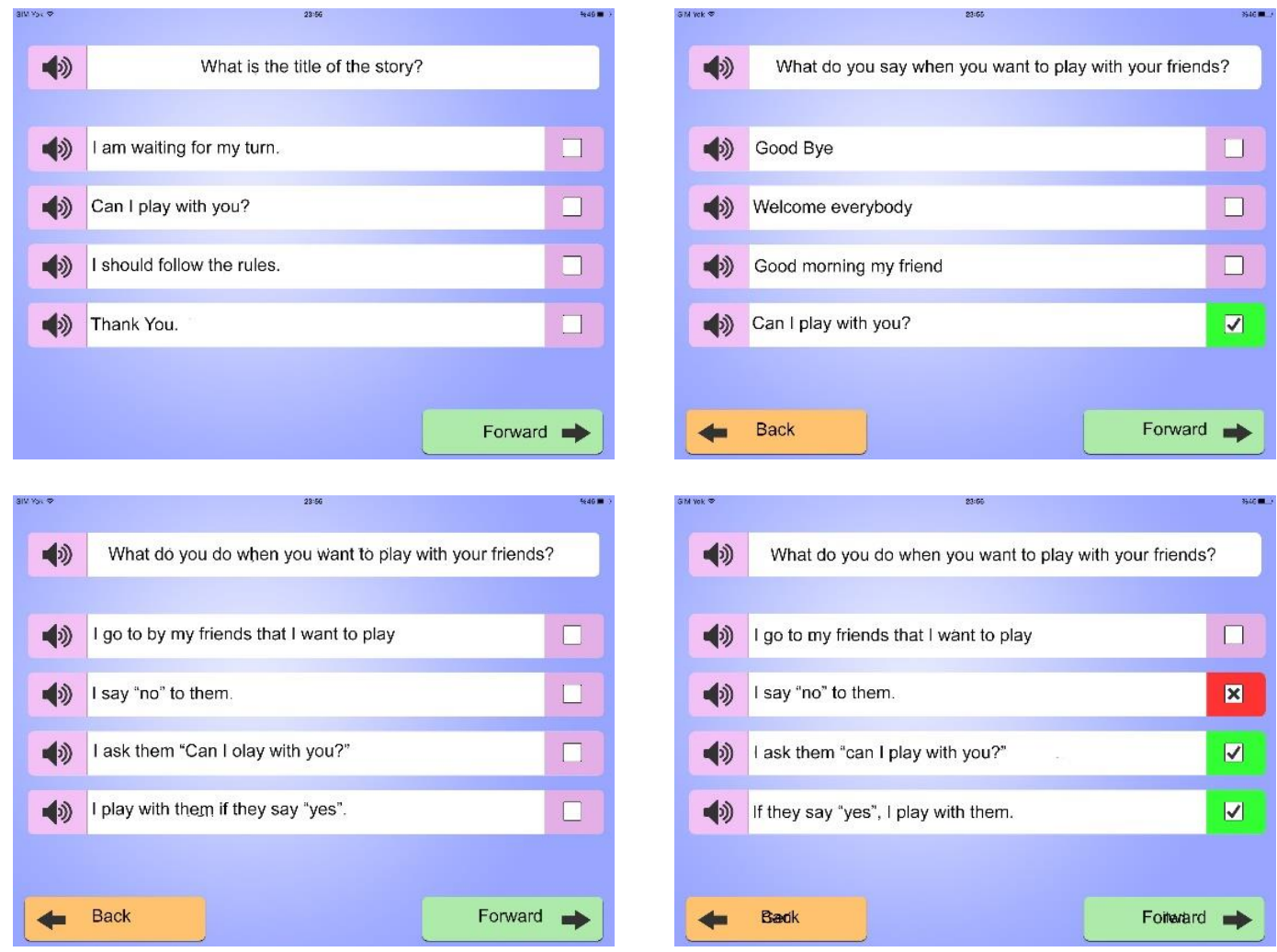

Figure 8. Reading Comprehension Questions

Page 16: Logout page: Different options are given on the logout page based on the needs of the participants. This page provides participants with the opportunity to go back to the previous page, re-read the story, or logout.

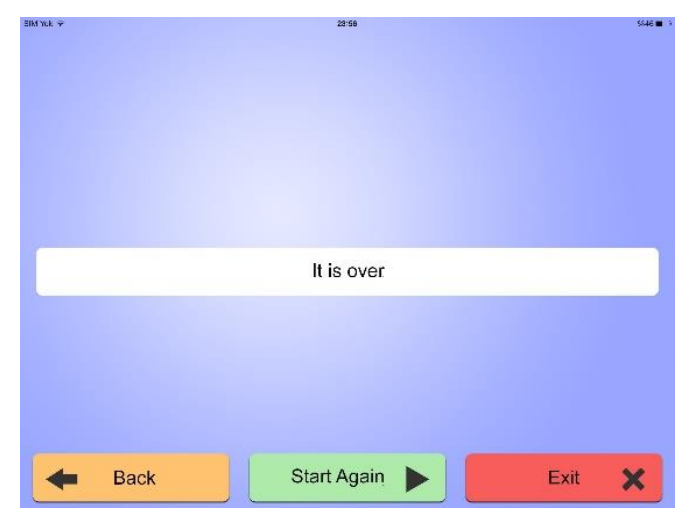

Figure 9. Logout Page

\section{Participants of the Design-based Research Process}

A total of 157 participants contributed to the current design-based research. That is, eight target students with ASD and their mothers, 13 teachers, 104 peers with typical development, 23 experts, and the first author of this manuscript participated in the process. Table 1 summarizes the details about the participants of the three remediation cycles. 
Out of eight participants, five attended inclusive education and three attended special education classes in a public school. Similarly, five of the teachers work in general education schools, while three work as special education teachers. A total of 104 peers with typical development were classmates of the participating students with ASD. There were a total of 23 experts who participated in the design and remediation cycles. Experts had experiences in different fields: Five in "special education, ASD, and social stories; eight in "single-subject designs"; two in "qualitative research"; five in "instructional technology and design based research"; and finally five in "graphics and materials design".

Table 1. Participants of the Design-based Research

\begin{tabular}{lccccccc}
\hline Participant & $\begin{array}{c}\text { 1st } \\
\text { remediation }\end{array}$ & $\begin{array}{c}\text { Participant } \\
\text { number }\end{array}$ & $\begin{array}{c}\text { 2nd } \\
\text { remediation }\end{array}$ & $\begin{array}{c}\text { Participant } \\
\text { number }\end{array}$ & $\begin{array}{c}\text { 3rd } \\
\text { remediation }\end{array}$ & $\begin{array}{c}\text { Participant } \\
\text { number }\end{array}$ & $\begin{array}{c}\text { Total } \\
\text { number }\end{array}$ \\
\hline Teachers & $\checkmark$ & 6 & $\checkmark$ & 7 & $\checkmark$ & 4 & 13 \\
Mothers & $\checkmark$ & 3 & $\checkmark$ & 5 & $\checkmark$ & 4 & 8 \\
Target & $\checkmark$ & 3 & $\checkmark$ & 1 & $\checkmark$ & 4 & 8 \\
students & & & & & & & \\
Peers & $\checkmark$ & 44 & & & $\checkmark$ & 60 & 104 \\
Experts & $\checkmark$ & 12 & $\checkmark$ & 7 & $\checkmark$ & 16 & 23 \\
Researcher & $\checkmark$ & 1 & $\checkmark$ & 1 & $\checkmark$ & 1 & 1 \\
\hline
\end{tabular}

\section{Research Context}

The "Cordova" tool by Apache was preferred over platform languages such as Objective C (iOSApple) or JAVA (Android-Google) to ensure the independence of the platform from different devices. Cordova is a mobile application development framework that uses an open-source code. The platform provides the opportunity to develop independent mobile applications using internet technologies such as HTML5, CSS3 and JavaScript. Applications developed through Cordova are placed in application shells exclusive to the platforms. Thanks to these shells, the codes can communicate with certain sensors such as touchscreens, GPS and accelerometers.

\section{Data Collection and Analysis}

During the design-based research and within the scope of the three remediation cycles, interviews, observations, questionnaires, log records, researcher diaries, and documents containing personal notes of the students were used to collect data from the target group (i.e., students, peers with typical development, mothers and teachers). In addition, all experts provided their feedback during different phases of the study.

Throughout the study, semi-structured interviews were conducted with mothers and teachers of eight target students with ASD. Participants were asked two open-ended questions. Researchers observed students with ASD in their natural settings, that is, at home and at their schools. Researchers kept field notes and video recordings during observations. Besides, researchers kept diaries and personal notes regarding the implementation. The questionnaires were constructed with multiple-choice items and open-ended questions to collect data regarding their participant perceptions on coping with mockery. Log-records were automatically 
recorded in tablet computers, which were also used to analyze the interaction patterns of target students with ASD.

Word clouds were used to analyze semi-structured interviews, observation notes, questionnaires, the researcher diary, and personal notes of the students. Prominent themes were descriptively analyzed based on their frequency counts. These word clouds were automatically created through "WordltOut." The textual data were revised to make it applicable to the program. That is, all letters in the textual data were transformed into lower-case letters. Then, prepositions, conjunctions, and punctuation marks were removed. After these modifications, the textual data were uploaded to the program, which created the word clouds. To analyze log records, data were transferred from tablets to personal computers. Participant data regarding the interface interaction were organized, grouped and analyzed using descriptive statistics. These data were digitized, and presented in tables and graphics, and interpreted accordingly.

\section{Findings}

In this section, findings on the design of interactive social stories are provided. The findings of each remediation cycle and the modifications based on the decisions in each cycle are explained below chronologically.

\section{Findings of the First Remediation Cycle}

The findings of the first remediation cycle were derived from the interviews with teachers and mothers along with the researcher notes regarding the first prototype. Two question forms with open-ended questions were given to 26 students and their responses were collected. Another group of 44 students were given a questionnaire, and their answers were analyzed. Their views on the prototype are explained below.

Views of teachers indicated that no changes were required regarding the general features of the application. Teachers maintained that they were satisfied with the current version. Their views are summarized through the word cloud provided in Figure 10.

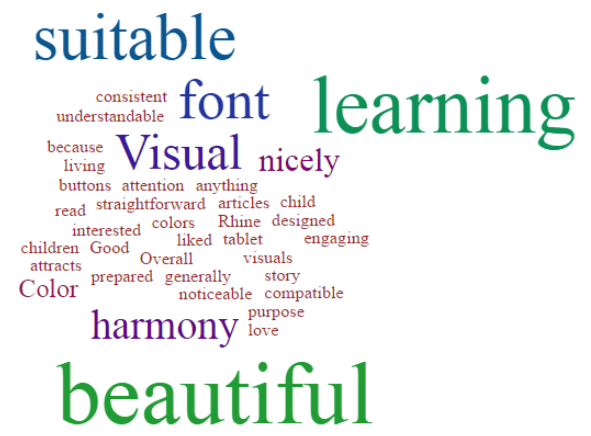

Figure 10. Teachers' Perceptions Regarding the First Prototype 
More specifically, "appropriateness of the colors," "readability of fonts," and "harmony/attractiveness of the images" led to positive views from teachers. They stated that the harmony between colors and the font made the prototype appealing. One of the teachers emphasized that "Colors are vivid and in harmony, it may attract both students and teachers" (Teacher 1). Another teacher described the visuals of the application as "good, with nothing negative standing out," and further characterized the application as "relevant with the learning outcomes" (Teacher 3).

In addition to these positive views, teachers also had some recommendations. These recommendations included using certain words instead of the current ones. They also advised placing a transition button to make the transition to reading comprehension questions clearer. One of the teachers stated "In my opinion, you may think about using the word 'angry' instead of 'upset.' I am not sure if they can understand what you mean." (Teacher 4); while another teacher (Teacher 5) recommended "to place a button to proceed to reading comprehension questions after reading the story."

Mothers also expressed positive opinions about the application. Furthermore, it is striking that the favorable features mentioned by mothers differed from those mentioned by teachers. Findings on the features that mothers found satisfactory are given in Figure 11 as a word cloud.

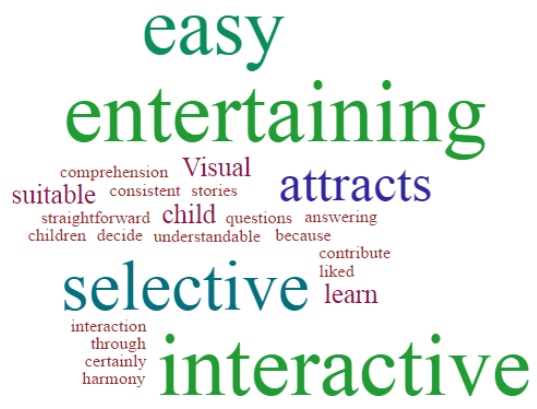

Figure 11. Mothers' Perceptions Regarding the First Prototype

The interactive nature of the prototype, opportunities to make choices, and easy and entertaining learning features were the positive views regarding the prototype. One of the mothers stated "My child learns with images, s/he will love it;" while another mother made a positive view stating "My child does not like reading but it will be attractive, as it is on tablet. The application is prepared with an appropriate style."

Views of the peers with typical development were also investigated for the phrases and words used in story statements. This investigation was particularly helpful for the topic "coping with mockery" as the story involved several delicate expressions. More specifically, 26 typically developing children were asked two open-ended questions about the subject discussed in the story. The questions were: "How do you feel when they mock you?" and "What do you do when they mock you?" After written views were collected from these students, a questionnaire was prepared based on their answers, and administered to a group of 44 children. Preferred statements were analyzed through a word cloud, which is provided in Figure 12. 


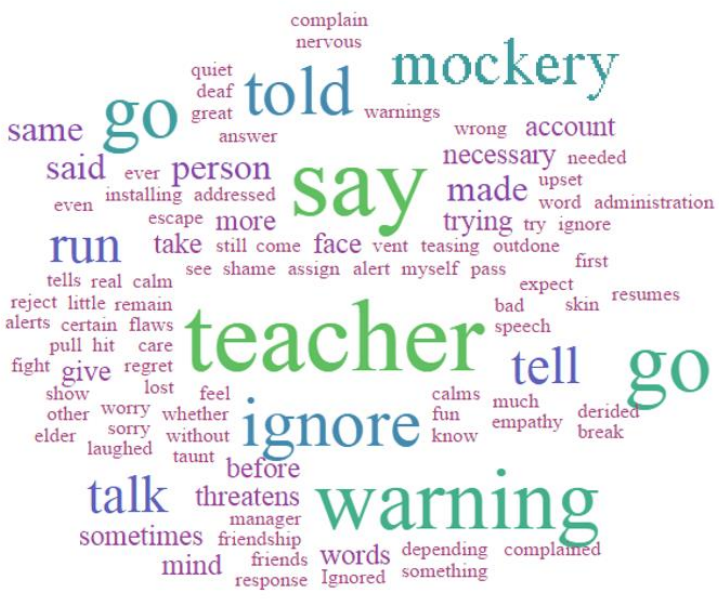

Figure 12. Statements Preferred by Peers

Based on the word cloud, the peers preferred the following statements: "mockery," "I would say/tell my teacher," "I would ignore," and "I would warn them." One of the peers said "I would warn him/her, and tell him/her not to mock me. If s/he continues I would inform my teacher, and would not be friends with him/her anymore;" while another peer stated that "... I would escape without saying anything. If it was someone I knew, I would talk back and then escape." Another peer displayed a similar approach and said: "I would be calm in the first place. Then I would run, and inform my teacher or head teacher. I would never talk to him/her again." These alternatives were evaluated by the field experts to be considered for further improvements.

\section{Decisions and Changes Made After the First Remediation Cycle}

After the data collection and analysis of the remediation cycle was over, expert opinions on this process were sought for. The statements were reviewed by experts in the light of the current literature, and the most frequently preferred words with no inconvenience were used. The buttons were decided to be prepared in three dimensions to make them user friendly. Furthermore, strict attention was paid to use universally common colors and signs on the buttons. Parallel to the statement indicating the difficulty in transition to the reading comprehension page, an extra page was added between the relevant pages and two buttons with "re-read" and "answer the questions" functions were included. Pastel colors were preferred over vivid ones. Based on the expert opinions, the clapping heard upon giving the correct answer to reading comprehension questions was decided to be removed. As the program characters could not be changed to add gestures and facial expressions, a graphic designer was hired to draw unique characters. Hence the design tool was required to be changed, and the "Cordova" was chosen instead. The outfits of the characters were chosen based on the uniforms used in the school where the study was conducted. Furthermore, the social stories were decided to be voiced by a peer from the same age group and education level. Additionally, log records were kept to track student interactions in the interactive social story practices. In this regard, a user login page was designed to appear before reading the stories. So, as soon as the participants entered their nicknames on the login page, their moves during the whole session would be recorded automatically. The log records of all pages were kept to investigate the nature of participant interactions with the social stories. 


\section{Findings of the Second Remediation Cycle}

In order to investigate the second remediation cycle, researcher notes, student log records and behavior records (videos) were used. Based on the researcher notes, teachers' perceptions regarding the usability of the prototype are provided in Figure 13.

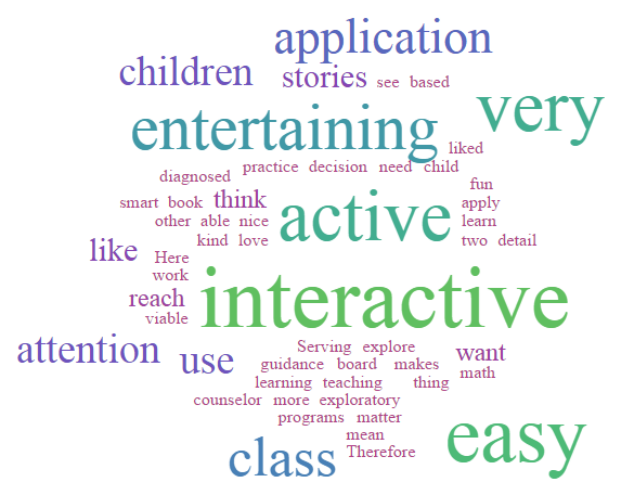

Figure 13. Teachers' Perceptions Regarding the Usability of the Prototype

Teachers stated the prototype was interactive, entertaining, user-friendly and made students active. It was pleasant that the mothers agreed with the issues emphasized by the teachers. As interpreted by teachers and mothers, the best feature of the prototype was its "being interactivity-oriented." Unlike mothers, the teachers stated that these stories were very easy to use and that they would benefit the students, as these stories provided an active and entertaining learning environment that proceeded parallel with student's own pace. Teachers further indicated that they wanted to use these stories with other children in their schools. One of the teachers made the following remark: "The application is very useful for the children you want to work with. I liked it very much. However, there are some introverted children with typical development too. They are also being mocked. We hear it from the teachers of other classes. As a counselor, I would love to use these stories for these cases too. In other words, I would love to use these stories with other children in need. In my opinion, the application is fun. So it would be easy to make connection with children too." (Teacher 4)

Data on the usability of the prototype were analyzed using log records such as the button use and reuse frequency. It was observed that the story was initiated without reading the user guide. However, the objective was to ensure that the user guide was visited before proceeding to stories. This issue drew attention as a usability matter, since it would be difficult for users to switch between pages in subsequent pages of the story if the user guide was not covered effectively.

\section{Decisions and Changes Made After the Second Remediation Cycle}

Based on the expert opinions, it was decided to configure the user guide of the prototype to show further details on how to use the "next" button. That is, the user guide was presented on the first hit and the function was initiated on the next hits. The objective was to ensure that students discovered the guide completely, and to avoid incidental use of buttons within the 
story. Through this update, the story was made to proceed only after the students have covered the user's guide.

\section{Findings of the Third Remediation Cycle}

The usability of the prototype was tested for two months and semi-structured interview questions, questionnaires, and researcher notes were analyzed in this period. During the interviews with mothers and teachers, views on the interactive social stories were elicited and displayed in Figure 14 and 15.

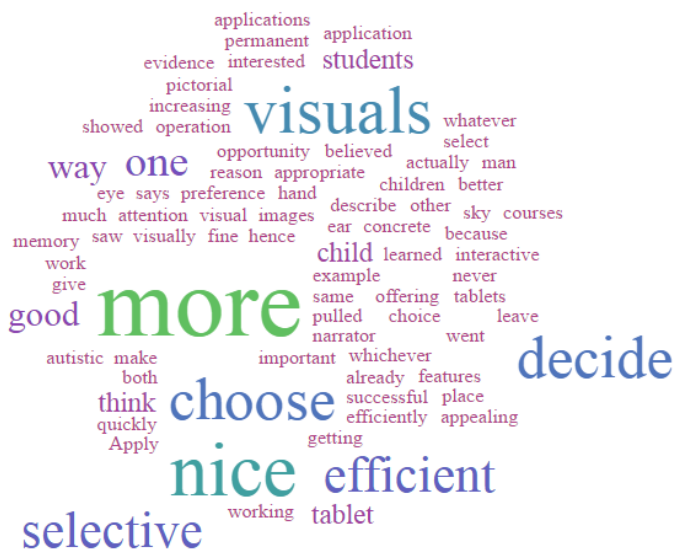

Figure 14. Mothers' Perceptions Regarding Interactive Social Stories

According to the word cloud, the mothers perceived the application as favorable. As the stories included images and provided the opportunity to make choices and decisions, they liked the materials. Another striking point mentioned by the mothers was the use of phrase "more" while comparing interactive social stories with the conventional ones. That is, they found interactive stories much more visual, entertaining, appealing, user-friendly and memorable.

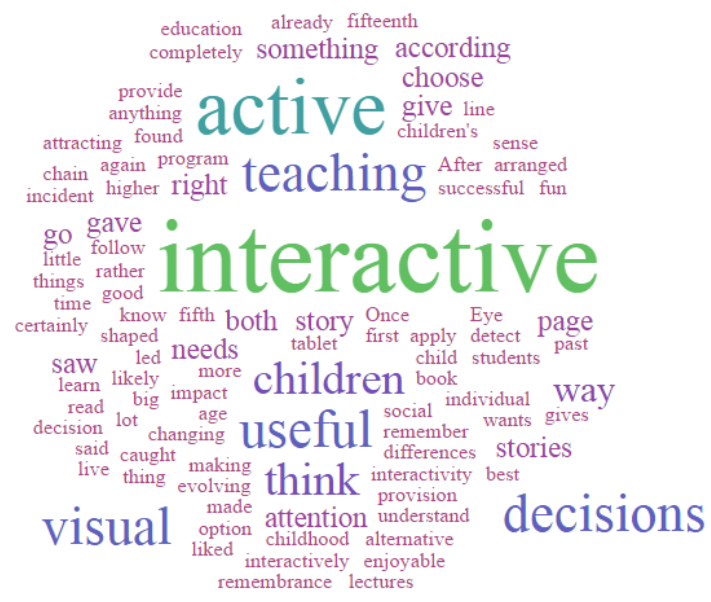

Figure 15. Teachers' Perceptions Regarding Interactive Social Stories

Teachers described the stories as interactive and argued that they gave students the opportunity to make their own choices. They further stated that the stories were relevant with student 
needs, included nice visuals and grabbed attention. For instance, one of the teachers stated that "The attention of children is better with these stories because they actively read the stories, which might make the stories easier to remember" (Teacher 2).

While introducing the materials during peer education, the researcher designated a volunteer student to illustrate how the stories could be accessed on the tablet, and asked him to read the stories. When students first saw these interactive social stories, they maintained that stories were like fun games, and they wanted to study with the stories as well: "Why don't we read them? Can we read them, too?" Some students wrote personal notes on whether their friends displayed the targeted behaviors during break times. Some examples from the peer notes are as follows: "Today Arda came to us while we were playing with a ball, and asked if he could play with us. And we told him that he could. We played together until the bell rang. First, we made passes to each other with a volleyball. Then we exercised as we exercise with you every day, because Arda liked basketball better. We got into a line. Then we shot the basket. Arda was having so much fun; he was very happy" (Peer 23). Another peer made the following statement regarding handling mockery: "Today, before the painting class which was the $5^{\text {th }}$ class, two naughty classmates poured water on Batu's drawing book. We entered the classroom and the students $A$ and $B$ mocked him. Batu was very upset when he saw his drawing book. I did not know what to do. Batu was very angry and told them not to mock him. He ran away quickly and escaped the class. I followed him. Teacher $N$ was in the common room. He told Teacher $N$ everything. And I explained what I saw." (Peer 18)

In addition to participant perspectives, log files were used to analyze the interactivity of participants with the instructional contents. A striking finding about the use of buttons provided in Table 2 was that no participant used re-read and restart buttons.

Table 2. Log Records about How to Use Interactivity Buttons

\begin{tabular}{|c|c|c|c|c|c|c|c|c|c|c|}
\hline \multirow{3}{*}{$\begin{array}{l}\text { Button } \\
\text { No }\end{array}$} & \multirow[t]{3}{*}{ Buttons } & \multirow{3}{*}{$\begin{array}{l}\text { Number } \\
\text { of } \\
\text { buttons }\end{array}$} & \multicolumn{8}{|c|}{ Participants } \\
\hline & & & \multicolumn{2}{|c|}{ Arda } & \multicolumn{2}{|c|}{ Batu } & \multicolumn{2}{|c|}{ Emre } & \multicolumn{2}{|c|}{ Gokmen } \\
\hline & & & $f$ & $\%$ & $f$ & $\%$ & $f$ & $\%$ & $f$ & $\%$ \\
\hline 1 & Back & 11 & 1 & 3 & 0 & 0 & 1 & 3 & 2 & 4 \\
\hline 2 & Listen & 13 & 39 & 100 & 52 & 100 & 72 & 100 & 57 & 88 \\
\hline 3 & Text boxes & 5 & 15 & 100 & 20 & 100 & 20 & 100 & 22 & 88 \\
\hline 4 & Speech bubbles & 5 & 15 & 100 & 20 & 100 & 20 & 67 & 10 & 40 \\
\hline 5 & Selection box & 1 & 3 & 100 & 4 & 100 & 6 & 100 & 5 & 100 \\
\hline 6 & Re-read & 1 & 0 & 0 & 0 & 0 & 0 & 0 & 0 & 0 \\
\hline 7 & Re-start & 1 & 0 & 0 & 0 & 0 & 0 & 0 & 0 & 0 \\
\hline \multicolumn{3}{|c|}{ Number of sessions } & \multicolumn{2}{|c|}{3} & \multicolumn{2}{|c|}{4} & \multicolumn{2}{|c|}{6} & \multicolumn{2}{|c|}{5} \\
\hline
\end{tabular}




\section{Decisions and changes made after the third remediation cycle}

In the third remediation cycle, experts analyzed why the re-read and restart buttons were not used, and concluded that these buttons should be kept, as participants with different personal qualifications may prefer to use these buttons in further practices.

The data collected from teachers, mothers, and students indicated no update requests related to the prototype in the third remediation cycle. Thus, the prototype was regarded as satisfactory, which was finalized without any further changes. Furthermore, in line with the requests made by the shareholders in the third remediation cycle, the application was planned to be uploaded to the internet and opened to access for mobile devices through cross-platform support. The objective of this process was to ensure that devices with different operating systems (e.g., iOS, Android) could run the program, which was aimed to be used by a greater number of users in future.

\section{Discussion and Conclusion}

The current study investigated the design and use of interactive social stories for skills teaching to adolescents with ASD. Findings indicated that interactive social stories were perceived as entertaining, reader-friendly, memorable and engaging. Prevalent comments made by both mothers and teachers revealed that interactive social stories were mostly "interactive" and "choice/decision-oriented". In addition, comments regarding the use of buttons, symbols and composition harmony on the materials were mostly positive as they were observed as striking, relevant and fun. Feedback from experts, primary caregivers and teachers helped the researchers to fine-tune the design further in each remediation cycle, which led them to create materials that were pertinent with the characteristics of the target group with ASD.

As frequently stated in the multimedia learning literature, learning process is facilitated through employing multiple symbol systems to serve different sensory modalities (Mayer, 1997; Paivio, 1990). Furthermore, learning would be more effective when interrelated and corresponding words and images are presented closely on a screen (Mayer, 2005). The current material employed these principles through employing images and texts in a way to meet the assumptions of contiguity principles. In addition to these media, narration was also provided. According to the expertise reversal effect of the Cognitive Load Theory (Kalyuga, Ayres, Chandler, \& Sweller, 2003; Sweller, 2008) employing different media sources of the same information may create a redundancy effect for high-ability learners. However, such an assistance might be quite crucial for the current target population who are considerably behind the typically developing peers.

In addition to the employment of a variety of media sources, the current materials provided the learners with an opportunity to choose among different multimedia sources or scenarios. This practice was on one hand in line with the individual differences principle of multimedia learning (Mayer, 2005). On the other hand, it helped learners interact with the learning content. Finally, the comprehensible, brief and real-like nature of the stories and texts is significant in terms of the comprehensibility of the message to be conveyed.

As summarized above, principles derived from multimedia learning, cognitive load and dualcoding were employed to address frequent problems faced in remediation cycles while finetuning the interactive social stories. Optimizing the materials upon implementing and testing 
them in actual conditions with desired target groups increase the empirical value of the current materials. In fact, testing a design with various participants within the scope of the remediation cycles in a design-based research endeavor, and evaluating findings in authentic settings increase the validity of instructional decisions. Thus, the current materials can be used effectively in similar target populations. Yet, learning and research trajectories are never finalized which should lead further researchers to improve the current materials in their unique implementation settings.

Contributions of an interdisciplinary expert group helped researchers to ameliorate the prototypes and implementations further. A fruitful cooperation revealed different viewpoints each leading to further improvements. A desired level of awareness raising was experienced, and transmission of multiple perspectives among the experts was sustained. In this regard, the design-based research endeavor improved the quality of both instructional implementations and the professional development opportunities among the experts.

In order to realize similar implementations in further studies, teacher training institutions should equip pre-service teachers with relevant skills to integrate contemporary technologies into their classroom practices. If pre-service teachers do not experience appropriate ICT use for instructional activities, they cannot be expected to implement such interventions in their unique environments (Akbulut, Odabasi \& Kuzu, 2011), which weakens the quality of other exemplary practices in instructional settings as well (Akbulut, 2010). In this regard, in addition to a multidisciplinary perspective on action research and special education, continuous professional development activities regarding ICT integration are crucial to diffuse exemplary practices.

The current study poses several limitations. First of all, only two skills were addressed with limited number of scenarios to pursue. In this regard, new skills and navigation options can be integrated into current materials to increase the quality of skill-teaching practices to individuals with ASD. Second, even though a relatively large population provided feedback regarding the effectiveness of current instructional materials, the actual implementation groups were relatively small. In this regard, experimental investigations with larger groups may help further scholars to understand the practical significance of the developed instruments. To help this purpose, current materials will be disseminated online as well. Third, the current implementation lasted for two semesters. Thus, longitudinal investigations are needed to validate the findings. Finally, subtitles are not used in the materials and their impact on the learning experience for a disabled group was not sought for. When multiple disabilities are on stage such ASD with hearing impairment, such a modification might be crucial. Thus, the current materials can be improved through addition of further multimedia sources to implement them with multiple disability groups.

\section{Acknowledgement}

This manuscript is derived from the first author's doctoral dissertation. The study was conducted through the financial support provided by Anadolu University Research Fund (Project ID: 1402E038). 


\section{References}

Akbulut, Y. (2010). A structural model proposal for Turkish faculties of education regarding ICT integration indicators. Contemporary Educational Technology, 1(4), 322-334.

Akbulut, Y., Odabasi, H.F., \& Kuzu, A. (2011). Perceptions of preservice teachers regarding the integration of information and communication technologies in Turkish education faculties. Turkish Online Journal of Educational Technology (TOJET), 10(3), 175-184.

American Psychiatric Association. (2012). DSM-5 Proposed criteria for autism spectrum disorder designed to provide more accurate diagnosis and treatment. Retrieved October 11, 2016 from http://www.dsm5.org/Documents/1203\%20Autism\%20Spectrum\%20Disorders\%20-\%20DSM5.pdf

Bannan-Ritland, B. (2003). The role of design in research: The integrative learning design framework. Educational Researcher, 32(1), 21-24.

Barab, S. (2006). Design-based research: A methodological toolkit for the learning scientist. R. K. Sawyer (Ed.), The Cambridge handbook of the learning sciences (pp. 151-170). Cambridge, UK: Cambridge University Press.

Barab, S. \& Squire, K. (2004). Design-based research: Putting a stake in the ground. The Journal of the Learning Sciences, 13(1), 1-14.

Brown, A. L. (1992). Design experiments: Theoretical and methodological challenges in creating complex interventions. Journal of the Learning Sciences, 2(2), 141-178.

Brownell, M. D. (2002). Musically adapted social stories to modify behaviors in students in autism: Four case studies. Journal of Music Therapy, 39(2), 117-144.

Chen, W. (2012). Multitouch tabletop technology for people with autism spectrum disorder: A review of the literature. Procedia Computer Science, 14, 198-207.

Collins, A. (1992). Towards a design science of education. In E. Scanlon \& T. O'Shea (Eds.), New directions in educational technology (pp. 15-22). Berlin: Springer-Verlag.

Design-Based Research Collective. (2003). Design-based research: An emerging paradigm for educational inquiry. Educational Researcher, 32(1), 5-8.

Garzotto, F., Paolini, P., \& Sabiescu, A. (2010). Interactive storytelling for children. In Proceedings of the 9th International Conference on Interaction Design and Children (pp. 356-359). ACM.

Gentry, T., Lau, S., Molinelli, A., Fallen, A., \& Kriner, R. (2012). The Apple iPod Touch as a vocational support aid for adults with autism: Three case studies. Journal of Vocational Rehabilitation, 37(2), 75-85.

Goodman-Scott, E. \& Carlisle, R. (2014). School counselors' roles in creating and Implementing social stories to serve students with autism spectrum disorder. Professional School Counseling, 18(1), 158-168.

Gray, C. A. (2010). The new social stories book. Arlington, TX: Future Horizons.

Gray, C. A. \& Garand, J. D. (1993). Social stories: Improving responses of students with autism with accurate social information. Focus on Autistic Behavior, 8, 1-10. 
Hagiwara, T. \& Myles, B. S. (1999). A multimedia social story intervention: Teaching skills to children with autism. Focus an Autism and Other Developmental Disabilities, 14(2), 8295.

Herbert, M. (2010). Finding new solutions for ELL assessments. Retrieved December 10, 2013 from http://www.districtadministration.com/article/finding-new-solutions-ellassessments

Hoadley, C. M. (2005). Design based research methods and theory building: A case study of research with SpeakEasy. Educational Technology, 45(1), 42-47.

Houghton, H. A. \& Willows, D. M. (1987). The psychology of illustration: Vol. 2, Instructional issues. New York: Springer-Verlag.

Johnson, L., Adams Becker, S., Cummins, M., Estrada, V., Freeman, A., \& Ludgate, H. (2013). Technology outlook for community, technical, and junior colleges 2013-2018: An NMC horizon project sector analysis. Austin, Texas: The New Media Consortium. Retrieved on 10 December 2013 from: http://www.nmc.org/pdf/2013-technology-outlookcommunity-colleges.pdf.

Kagohara, D. M., Sigafoos, J., Achmadi, D., O’Reilly, M. F., \& Lancioni, G. (2012). Teaching children with autism spectrum disorders to check the spelling of words. Research in Autism Spectrum Disorders, 6, 304-310.

Kalyuga, S., Ayres, P., Chandler, P., \& Sweller, J. (2003). Expertise reversal effect. Educational Psychologist, 38(1), 23-31.

Karkhaneh, M., Clark, B., Ospina, M. B., Seida, J. C., Smith, V., \& Hartling, L. (2010). Social Stories to improve social skills in children with autism spectrum disorder: A systematic review. Autism, 14(6) 641-662.

Lundby, K. (2008). Digital storytelling, mediatized stories: Self-representations in new media (Vol. 52). New York: Peter Lang Publishing.

Mandl, H. \& Levin, J. R. (Eds.). (1989). Knowledge acquisition from text and pictures. Amsterdam: Elsevier.

Mayer, R. E. (1997). Multimedia learning: Are we asking the right questions? Educational Psychologist, 32(1), 1-19.

Mayer, R. E. (2005). Introduction to Multimedia Learning. In R. E. Mayer (ed.), The Cambridge Handbook of Multimedia Learning (pp. 1-16). New York: Cambridge University Press.

Mayer, R. E. \& Moreno, R. (1998). A split-attention effect in multimedia learning: Evidence for dual processing systems in working memory. Journal of Educational Psychology, 90(2), 312-320.

Mayer, R. E. \& Sims, V. K. (1994). For whom is a picture worth a thousand words? Extensions of a dual-coding theory of multimedia learning. Journal of Educational Psychology, 86(3), 389-460.

Miller, G. A. (1956). The magical number seven, plus or minus two: Some limits on our capacity for processing information. Psychological Review, 63(2), 81.

More, C. (2008). Digital stories targeting social skills for children with disabilities multidimensional learning. Intervention in School and Clinic, 43(3), 168-177. 
Moreno, R. \& Mayer, R. E. (1999). Cognitive principles of multimedia design: The role of modality and contiguity. Journal of Educational Psychology, 91(2), 358-368.

Mukti, N. A. \& Hwa, S. P. (2004). Malaysian Perspective: Designing interactive multimedia learning environment for moral values education. Educational Technology \& Society, 7(4), 143-152.

National Autism Center (NAC). (2015). National standards report 2. Randolph, Massachusetts: National Autism Center.

Ozdemir, S. (2008). Using multimedia social stories to increase appropriate social engagement in young children with autism. The Turkish Online Journal of Educational Technology, $7(3), 80-88$.

Paivio, A. (1990). Mental representations: A dual coding approach. Oxford: Oxford University Press.

Ramdoss, S., Lang, R., Fragale, C., Britt, C., O’Reilly, M., Sigafoos, J. et al. (2012). Use of computer-based interventions to promote daily living skills in individuals with intellectual disabilities: A systematic review. Journal of Developmental and Physical Disabilities, 24(2), 197-215.

Rao, S. M. \& Gagie, B. (2006). Learning through seeing and doing: Visual supports for children with autism. Teaching Exceptional Children, 38(6), 26-33.

Reeves, T. C. (2000). Socially responsible educational research. Educational Technology, 40(6), 19-28.

Richter, S. \& Test, D. (2011). Effects of multimedia social stories on knowledge of adult outcomes and opportunities among transition-aged youth with significant cognitive disabilities. Education and Training in Autism and Developmental Disabilities, 46(3), 410424.

Sani-Bozkurt, S. (2016). Design and effectiveness of technology enhanced interactive media in teaching social skills for children with autism spectrum disorder (Unpublished doctoral dissertation). Eskisehir, Turkey: Anadolu University Graduate School of Educational Sciences.

Sansosti, F. \& Powell-Smith, K. A. (2008). Using computer-presented social stories and video models to increase the social communication skills of children with high functioning autism spectrum disorders. Journal of Positive Behavior Interventions, 10(3), 162-178.

Schnotz, W. (1993). Introduction to special issue on comprehension of graphics in texts. Learning and Instruction, 3, 151-155.

Schwartz, D. L., Lin, X., Brophy, S., \& Bransford, J. D. (1999). Toward the development of flexibility adaptive instructional designs. In C. M. Reigeluth (Ed.), Instructional-design theories and models, Vol. II, (pp. 183-213). Mahwah, NJ: Lawrence Erlbaum.

Shah, N. (2011). Special education pupils find learning tool in iPad applications. Education Week. Retrieved on 10 December 2013 from: http://www.edweek.org/dd/articles/ 2011/10/19/01speced.h05.html.

Shavelson, R. J., Phillips, D. C., Towne, L., \& Feuer, M. J. (2003). On the science of education design studies. Educational Researcher, 32(1), 25-28. 
Shukla-Mehta, S., Miller, T., \& Callahan, K. J. (2010). Evaluating the effectiveness of video instruction on social and communication skills training for children with autism spectrum disorders: A review of the literature. Focus on Autism and Other Developmental Disabilities, 25(1), 23-36.

Sweller, J. (1988). Cognitive load during problem solving: Effects on learning. Cognitive Science, 12(2), 257-285.

Sweller, J. (2008). Human cognitive architecture. In J. M. Spector, M. D. Merrill, J. J. G. Van Merriënboer \& M. P. Driscoll (Eds.), Handbook of Research on Educational Communications and Technology (3 ${ }^{\text {rd }}$ edition) (pp. 369 - 381). Hillsdale, NJ: Erlbaum.

Wang, F. \& Hannafin, M. J. (2005). Design-based research and technology-enhanced learning environments. Educational Technology Research and Development, 53(4), 5-23.

Wheeler, K. L. (2005). The power of social stories: A strategy for students with autism spectrum disorder (Unpublished master's thesis). Fullerton, CA: California State University.

van den Akker, J. (1999). Principles and methods of development research. In J. van den Akker, N. Nieveen, R. M. Branch, K. L. Gustafson \& T. Plomp (Eds.), Design methodology and developmental research in education and training (pp. 1-14). The Netherlands: Kluwer Academic Publishers.

Correspondence: Sunagul Sani-Bozkurt, Ph.D., Research Assistant, Department of Special Education, Faculty of Education, Anadolu University, Yunus Emre Campus, Eskisehir, Turkey 